This is a self-archived - parallel published version of this article in the publication archive of the University of Vaasa. It might differ from the original.

\title{
Managing Multitype Capacity Resources For Frequency Regulation In Unit Commitment Integrated With Large Wind Ramping
}

Author(s): Hemmati, Reza; Mehrjerdi, Hasan; Shafie-khah, Miadreza; Siano, Pierluigi; Catalao, Joao P.S.

Title: $\quad$ Managing Multitype Capacity Resources For Frequency Regulation In Unit Commitment Integrated With Large Wind Ramping

Year: $\quad 2020$

Version: Accepted version

Copyright (C)2020 IEEE. Personal use of this material is permitted. Permission from IEEE must be obtained for all other uses, in any current or future media, including reprinting/republishing this material for advertising or promotional purposes, creating new collective works, for resale or redistribution to servers or lists, or reuse of any copyrighted component of this work in other works.

\section{Please cite the original version:}

Hemmati, R., Mehrjerdi, H., Shafie-khah, M., Siano, P. \& Catalao, J.P.S. (2020). Managing Multitype Capacity Resources For Frequency Regulation In Unit Commitment Integrated With Large Wind Ramping. IEEE Transactions on Sustainable Energy, 1-8. https://doi.org/10.1109/TSTE.2020.3017231 


\title{
Managing Multitype Capacity Resources for Frequency Regulation in Unit Commitment Integrated with Large Wind Ramping
}

\author{
R. Hemmati, H. Mehrjerdi, Senior Member, IEEE M. Shafie-khah, Senior Member, IEEE, \\ P. Siano, Senior Member, IEEE, and J.P.S. Catalão, Senior Member, IEEE
}

\begin{abstract}
An efficient unit commitment planning must consider frequency regulation capacity in the model. Such models are more complicated under a high penetration level of renewable energy because of renewable ramping and uncertainty. This paper addresses these issues in the unit commitment. The proposed model for unit commitment considers uncertainty and ramping of wind power, frequency regulation capacity, spinning reserve, demand response, and pumped-storage hydroelectricity. Two reserve capacities including primary frequency regulation and spinning reserve are designed to handle the intermittency and ramping of renewable energies. In order to optimize the costs, the pumpedstorage hydroelectricity and demand response program are also included to deal with ramping and uncertainty. The numerical results specify that the arrangement of frequency regulation capacity, pumped-storage system and demand response can effectively tackle both the ramping and uncertainty. The system includes 10-generator with total power equal to $1070 \mathrm{MW}$ and one wind generator with $300 \mathrm{MW}$ power. The initial wind integration level is about $28 \%$. It is verified that decreasing the frequency regulation capacity by $10 \%$ reduces wind integration level by $94 \%$. The demand response and pumped-storage increase wind integration level by $10 \%$ and $16 \%$; while both together increase wind integration by $25 \%$ compared to the initial level. The wind integration level without large wind ramping can be increased up to $200 \%$.
\end{abstract}

Index Terms-Demand Response, Frequency Regulation, Pumped-Storage Hydroelectricity, Unit Commitment, Wind Integration, Wind Ramping.

\begin{tabular}{ll} 
& \multicolumn{1}{c}{ NOMENCLATURE } \\
\hline Indexes & \\
\hline$g$ & Index of generators \\
$s$ & Index of scenarios \\
$t$ & Index of time sections \\
Sets & \\
$G N$ & Set of generators \\
$S C$ & Set of scenarios \\
$T P$ & Set of time sections \\
\hline Parameters & \\
\hline$C_{f c}^{g}$ & Fixed cost of generator $(\$ / \mathrm{h})$ \\
$C_{v c}^{g}$ & Variable cost of generator $(\$ / \mathrm{MWh})$ \\
$C_{s u}^{g}$ & Startup cost $(\$ / \mathrm{h})$ \\
$C_{d r}^{t}$ & Load curtailment cost $(\$ / \mathrm{MWh})$ \\
$D_{o c}^{u c}$ & Daily operational cost of system $(\$ /$ day $)$ \\
\hline
\end{tabular}

Reza Hemmati is with Department of Electrical Engineering, Kermanshah University of Technology, Kermanshah, Iran (r.hemmati@kut.ac.ir)

Hasan Mehrjerdi is with Electrical Engineering Department, Qatar University, Doha, Qatar (hasan.mehrjerdi@qu.edu.qa)

Miadreza Shafie-khah is with School of Technology and Innovations, University of Vaasa, 65200 Vaasa, Finland (mshafiek@univaasa.fi)

Pierluigi Siano is with Department of Management \& Innovation Systems, University of Salerno, 84084 Salerno, Italy (psiano@unisa.it)

Joao P.S. Catalão is with Faculty of Engineering of the University of Porto and INESC TEC, 4200465 Porto, Portugal (cataloo@feup pt)

\begin{tabular}{ll}
\hline$E_{r e s}$ & Rated capacity of pumped-storage system (MWh) \\
$F_{r c}^{t}$ & Total capacity for frequency regulation (MW) \\
$K_{d r}^{\min }$ & Minimum level for curtailable load (MW) \\
$K_{d r}^{\max }$ & Maximum level for curtailable load (MW) \\
$L_{d}^{t}$ & Load demand (MW) \\
$P_{r e s}$ & Rated power of pumped-storage system (MW) \\
$P_{w}^{s, t}$ & Wind power (MW) \\
$P_{r b}^{s}$ & Probability of scenario \\
$P_{t}^{\min }$ & Minimum power of generator (MW) \\
$P_{t}^{\text {max }}$ & Maximum power of generator (MW) \\
$P_{r d}^{g}$ & Ramp down power of generator (MW/h) \\
$P_{r u}^{g}$ & Ramp up power of generator (MW/h) \\
$S_{r c}^{t}$ & Total spinning reserve capacity (MW) \\
$T_{p}$ & Duration of time period (Minute) \\
$\eta_{e s}^{s}$ & Efficiency of pumped-storage system (\%) \\
\hline Variables & \\
\hline$E_{e s}^{s, t}$ & Energy of pumped-storage system (MWh) \\
$K_{d r}^{s, t}$ & Percentage of load curtailment (\%) \\
$P_{o}^{s, g, t}$ & Output power of generator (MW) \\
$P_{t}^{g, t}$ & Nominal capacity of generator (MW) \\
$P_{m}^{g, t}$ & Dispatched power to supply demand (MW) \\
$P_{r}^{g, t}$ & Capacity for spinning reserve (MW) \\
$P_{f}^{g, t}$ & Capacity for frequency regulation (MW) \\
$P_{s s}^{s, g, t}$ & Produced power by frequency regulation section \\
$P_{d e s}^{s, t}$ & (MW) \\
$P_{c e s}^{s, t}$ & Discharging power of pumped-storage system (MW) \\
$u_{s d}^{g, t}$ & Charging power of pumped-storage system (MW) \\
$u_{o n}^{g, t}$ & Binary variable showing shutdown of generator \\
$u_{s u}^{g, t}$ & \\
\hline & Binary variable showing on-off state of generator \\
\hline & \\
\hline
\end{tabular}

\section{INTRODUCTION}

The introduction is presented in five subsections that reviews the problem from different perspectives.

\section{A. Wind energy penetration}

Together with an increasing penetration level of wind energy in electric power systems, some negative aspects and challenges of wind energy have been brought to light. The main problem of wind energy is about its intermittency [1]. The other issue related to wind energy is on the subject of wind energy ramp-up and ramp-down [2]. Sometimes, wind energy shows the fluctuations with large magnitude at very 
short time periods ranging from second to minute, namely "ramping event" [3]. Such fast ramp-up and ramp-down make significant impacts on power system operation (e.g., unit commitment) and the network must have enough resiliency (e.g., frequency regulation capacity) to cope with such oscillations [4]. The variability of wind energy can be managed by thermal units including up/down ramping capacity. Such ramping capacity of thermal units can deal with the ramping events in the renewable energies. The combination of thermal units with energy storage devices and demand response program is more effective to cope with the aforementioned variability [5]. The wind power ramp events make impacts on the economic and reliable operation of the electrical network. It is therefore important to detect these ramping events. The optimized swinging door algorithm is one the proper techniques to detect the wind power ramping events [6]. The wind energy may be utilized together with a pumped storage system. The water storage can properly deal with wind power variations. Such coordination operation needs wind-power forecasting [7].

\section{B. Frequency regulation service}

The mentioned ramping power needs proper frequency regulation service. The network frequency control is often made by a three-level control scheme including primary, secondary, and tertiary frequency control [8]. The primary control must handle the imbalances between generation and load and stabilize the frequency. The network needs proper capacity for primary control in the presence of large ramps in renewable power output. However, devoting large capacity to the frequency regulation decreases the ability of generators to produce power and supply the demand, and it may increase the operational cost of the network [9].

\section{Unit commitment}

The unit commitment is a short-term programming that determines the produced power by each generation unit [10]. The unit commitment often models the practical constraints of generating systems such as ramp-up and ramp-down, minimum up-time and down-time, and startup cost [11]. The frequency regulation capacity is an important part of the generation capacity. As a result, some researchers have tried to consider primary frequency control in the unit commitment [12]. It is very important to design proper frequency regulation capacity for the system. The small capacity for frequency regulation decreases the operational cost of the network because the generators are not forced to schedule their capacities for frequency regulation reserve, but such a system cannot handle large power fluctuations. On the other hand, large capacity for frequency regulation increases the operational cost of the network but makes the network robust against large power fluctuations such as ramping events. Scheduling a proper reserve capacity for frequency regulation in the thermal generating systems can avoid load shedding [13].

The frequency regulation is very important in the new interconnected energy systems. In the energy systems, the interaction among various energy systems and energy hubs is an outstanding challenge. The virtual energy hub may provide a new opportunity to handle the challenges and providing the opportunity for taking part in the local energy markets [14]. However, the interaction of such systems needs accurate frequency regulation scheme. Such interconnection may be among various home energy systems and hubs that are located in the neighborhood network. Such energy systems often try to maximize their financial profit through shaving the peak load demand of the network [15]. The demand response is an efficient tool to deal with energy management issues. The demand response programs often shift load demand from on-peak time periods to the off-peak hours resulting in less operating cost in the networks. The price-responsive bidding method is modeled as a costenvironmental effective demand response program by [16]. Such demand response programs are also very effective in the multiple home and microgrid systems. These interconnected home-microgrid systems may cooperate with each other through forming a transactive energy framework. The demand and renewable fluctuations may be addressed by demand-side management strategies [17]. The electric vehicles are also one of the mature technologies to deal with energy issues. The vehicle-to-grid technologies need the collaboration of the end users, the vehicle owners, the network operator and policy makers. The battery degradation is one of the problems related to vehicle-to-grid systems and it can be minimized by the efficient planning [18].

The ramping events and uncertainty related to the wind energy sources can be properly dealt by gas fired units because of their high ramping capacity. The storage technologies like compressed air energy storage and demand response program may also be integrated to improve the system operation [19].

The unit commitment regularly deals with generation system operation. However, the transmission network issues often make impacts on the generation system operation. For instance, the electricity transmission bottleneck may create some issues in the electric power systems when the generation system produces large amount of electricity and the grid is saturated. The large amount of the renewable integration may increase issues. It is therefore more accurate to consider network expansion planning together with renewable integration and generation system operation in order to avoid network issues like transmission bottleneck.

\section{Motivations and contributions of paper}

The ramping event and frequency regulation capacity are some key challenges in the unit commitment. The problem is more complicated under a high penetration level of renewable energy because a large frequency regulation capacity is required to handle large ramping events. The unit commitment presented by this paper considers many items including high penetration level of wind energy, uncertainty of wind energy, large ramp-up and ramp-down of wind power, frequency regulation capacity, spinning reserve, demand response programs, and pumped-storage hydroelectricity. The frequency regulation capacity and spinning reserve are supported by the generators. Energy storage systems and demand response programs are incorporated to cover renewable ramping as well as uncertainty. 
The main innovation of this paper is to model and study the large ramps and uncertainties of wind energy in the unit commitment under high penetration level of wind energy. These issues are handled by different capacity resources including demand response program, pumped-storage hydroelectricity, frequency regulation capacity, and spinning reserve. The details of these items can be presented as follows;

- The practical issues related to wind energy including large rampup and ramp-down, high penetration level, and uncertainty are simultaneously modeled in the unit commitment problem.

- Different capacity resources including demand response program, pumped-storage hydroelectricity, frequency regulation capacity, and spinning reserve are included to handle the wind ramping and uncertainty.

- The practical constraints of generating systems such as ramp-up and ramp-down, minimum up-time and down-time, and startup cost are incorporated.

- The wind energy and loading energy profile are modeled in 15minute time-interval to increase the accuracy of the model.

- Investigating the impacts of frequency regulation capacity and wind penetration level on each other.

- Examining the effects of demand response program and pumpedstorage hydroelectricity on wind penetration level, costs, frequency regulation capacity, and spinning reserve.

- This paper simultaneously investigates the combination of all mentioned items and studies their mutual impacts on each other. The included items in the unit commitment are wind penetration level, wind uncertainty, wind ramping events, frequency regulation, spinning reserve, demand response program, pumped-storage hydroelectricity, and practical constraints of thermal generating units.

\section{E. Organization of the paper}

Apart from the introduction section, rest of the paper is organized as follows sections. Section 2 presents the ramping event in the renewable energy. Section 3 evaluates the interaction between the frequency regulation and ramping events. The unit commitment problem is modeled and introduced in the section 4 . This section also models the demand response and energy storage systems. The test network is introduced in the section 5 and the numerical results are given in the section 6 . This section presents the results through nine subsections. The final section is devoted to the conclusion.

\section{RAMPING EVENT IN RENEWABLE ENERGY}

Integration of large-scale renewable energy into power grids is one of the concerns in modern power systems. The high penetration level of wind and solar energy could create large ramp-up and ramp-down in the output power of these resources [3]. The network must be able to handle such large ramps. The ramping power can be created by wind, solar or even load. In order to deal with such large ramps, the first step is to detect them, and the second step is to consider them in the network operation such as unit commitment.

The ramp detecting methods have been proposed to detect large power ramps in the network. The wind power ramping could be detected by recursive dynamic programming [20], swinging door algorithm [3], or data mining. The artificial intelligence methods can also be applied to detect wind ramps [21]. The wind ramps occur in short time periods and in order to simulate such ramps, the simulations must be carried out on short time intervals such as 15-minute time sections [3].

The up-ramp is expressed as the increase in output power of renewable resource which is greater than $20 \%$ of the installed capacity within a time period less than 4-hour. On the other hand, the down-ramp is denoted as the decrease in output power of renewable resource that is greater than $15 \%$ of the installed capacity at time period less than 4-hour [12]. A typical wind power with two ramp events is shown in the Fig. 1. The data shows a typical $200 \mathrm{MW}$ wind farm [22]. Two ramp-up are occurred at the time intervals 21 and 41 , and two ramp-down occur at the time intervals 25 and 57. Such quick and large-magnitude ramps need advanced control strategy for the frequency regulation.

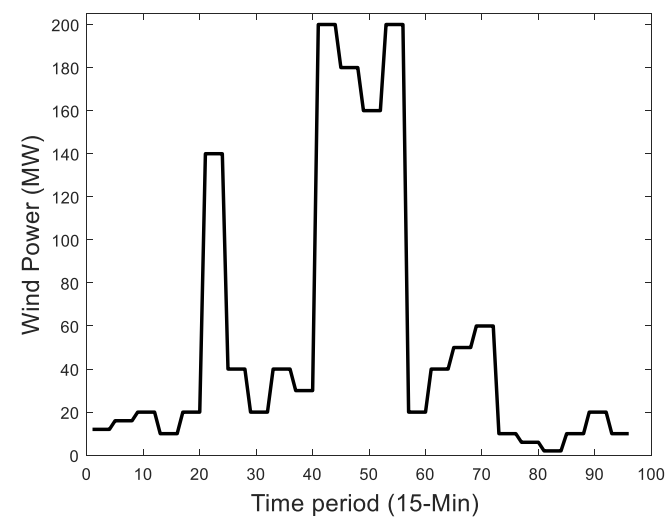

Fig. 1. $200 \mathrm{MW}$ wind farm with large ramp up and down.

\section{FREQUENCY REGULATION AND RAMPING EVENTS}

In the electric generation system, the frequency control is classified in three levels namely primary, secondary, and tertiary frequency control [23]. The conceptual framework of these levels is depicted in Fig. 2. The primary control is locally situated on the generators and it is automatic. It compensates the imbalance between generation and load to control the frequency. The primary control does not restore the frequency to the nominal level and only stabilizes the frequency and prevents strict dropping. The secondary control is a slower control system with centralized control. It often comprises more capacity to restore the frequency to the nominal level and release the capacity of primary control for the next incidents. The secondary control is also known as automatic generator control (AGC). The tertiary control is a slower control system that releases the capacity of secondary control for next incidents. After tertiary control, the redispatch of generation is carried out at the next time period to handle new loading condition [24].

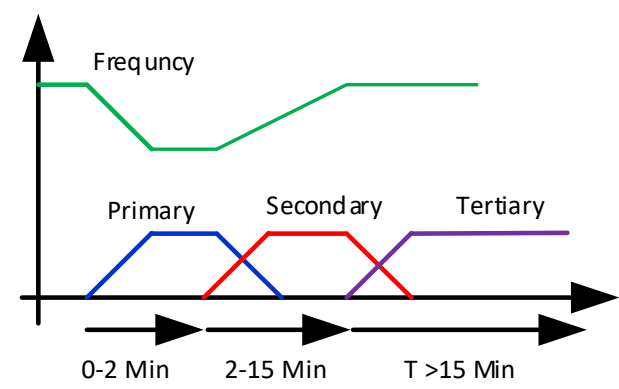

Fig. 2. Primary, secondary, and tertiary frequency control. 


\section{THE UNIT COMMITMENT PROBLEM}

The proposed unit commitment is studied for the thermal units and the objective is to minimize the fuel and startup costs related to the thermal units. The proposed problem is expressed as mixed-integer linear programming that aims to minimize the objective function given by (1). This objective function presents the total plan cost. The first term of the objective function represents the fuel cost, the second term indicates the startup cost, and the last term is the cost for a demand response program [25].

$$
\begin{aligned}
& D_{o c}^{u c}=\sum_{s \in S C}\left(\left[\sum_{t \in T P} \sum_{g \in G N}\left(\begin{array}{l}
C_{f c}^{g} \times u_{o n}^{g, t}+ \\
P_{o}^{s, g, t} \times C_{v c}^{g} \times T_{p}
\end{array}\right)\right] \times P_{r b}^{s}\right)+ \\
& \sum_{t \in T P} \sum_{g \in G N}\left(C_{s u}^{g} \times u_{s u}^{g, t}\right)+\sum_{s \in S C}\left(\left(\sum_{t \in T P}\left(K_{d r}^{s, t} \times L_{d}^{t} \times C_{d r}^{t}\right)\right) \times P_{r b}^{s}\right)
\end{aligned}
$$

The capacity of each generator is used to supply the demand, or as spinning reserve, or as frequency regulation capacity. This point is shown in (2). The binary variable showing the ON-OFF state of generators is defined by (3) [13].

$$
\begin{aligned}
& P_{t}^{g, t}=P_{m}^{g, t}+P_{r}^{g, t}+P_{f}^{g, t} \quad \forall t \in T P, g \in G N \\
& u_{o n}^{g, t}=\left\{\begin{array}{ll}
1 & P_{m}^{g, t}>0 \\
0 & P_{m}^{g, t}=0
\end{array} \quad \forall t \in T P, g \in G N\right.
\end{aligned}
$$

In (4) and (5), it is confirmed that if the generator is off, then it cannot take part in frequency regulation and spinning reserve capacities. Only the generators that work as ON state are allowed to supply the frequency regulation and spinning reserve capacities. These equations model the generators onoff states.

$$
\begin{aligned}
& \left\{\begin{array}{ll}
P_{r}^{g, t}>0 & \text { if } u_{o n}^{g, t}=1 \\
P_{r}^{g, t}=0 & \text { if } u_{o n}^{g, t}=0
\end{array} \quad \forall t \in T P, g \in G N\right. \\
& \left\{\begin{array}{ll}
P_{f}^{g, t}>0 & \text { if } u_{o n}^{g, t}=1 \\
P_{f}^{g, t}=0 & \text { if } u_{o n}^{g, t}=0
\end{array} \quad \forall t \in T P, g \in G N\right.
\end{aligned}
$$

The spinning reserve at each time interval is calculated by (6), and the frequency regulation capacity is denoted by (7) [10]. These two equations model the reserve capacities of the generators.

$$
\begin{aligned}
\sum_{g \in G N}\left(P_{r}^{g, t}\right)=S_{r c}^{t} & \forall t \in T P \\
\sum_{g \in G N}\left(P_{f}^{g, t}\right)=F_{r c}^{t} & \forall t \in T P
\end{aligned}
$$

The frequency regulation capacity is responsible for regulating the frequency and handling the imbalances between load and generation. At each time interval, some portion of frequency regulation capacity may be utilized to fix the frequency. This portion must be lower than the frequency regulation capacity as shown by (8). As a result, the output power of generators at each time consists of two terms as shown by (9). The first part is required to supply the frequency regulation capacity and the second term is required to supply the load demand. The capacity devoted to the reserve capacity is modeled here.

$$
\begin{aligned}
& P_{s s}^{s, g, t} \leq P_{f}^{g, t} \quad \forall s \in S C, t \in T P, g \in G N \\
& P_{o}^{s, g, t}=P_{s s}^{s, g, t}+P_{m}^{g, t} \quad \forall s \in S C, t \in T P, g \in G N
\end{aligned}
$$

The power balance is modeled by (10). The demand response program is modeled as a curtailable load that must lie between the minimum and maximum levels as defined by (11).

$$
\begin{aligned}
& \sum_{g \in G N}\left(P_{m}^{g, t}\right)+P_{w}^{s, t}+\sum_{g \in G N}\left(P_{s s}^{s, g, t}\right)+ \\
& P_{c e s}^{s, t}-P_{d e s}^{s, t}=L_{d}^{t} \times\left(1-K_{d r}^{s, t}\right) \quad \forall s \in S C, t \in T P \\
& K_{d r}^{\min } \leq K_{d r}^{s, t} \leq K_{d r}^{\max } \quad \forall s \in S C, t \in T P
\end{aligned}
$$

Two time-intervals are simulated by this paper. The onehour time interval for energy dispatch and 15-minute time period for wind fluctuations. In (12), it is confirmed that the energy dispatch of generators is similar in the four consecutive time intervals that is equal to one hour. However, the other parameters such as frequency regulation, spinning reserve, storage operation, and demand response work on 15-minute time intervals.

$$
P_{m}^{g, t}=P_{m}^{g, t+1}=P_{m}^{g, t+2}=P_{m}^{g, t+3} \forall t \in[1,5,9,13, \ldots, 85,89,93], g \in G N
$$

\section{A. Practical characteristics of power plants}

The practical characteristics of the thermal power plants like ramp up-down, power limit, and minimum up-down time are modeled here. The capacity of each generator is limited by minimum-maximum power as (13). The ramp-up and rampdown power of generators are modeled by (14) and (15), respectively [26].

$$
\begin{aligned}
& \left(P_{t}^{\min } \times u_{o n}^{g, t}\right) \leq P_{t}^{g, t} \leq\left(P_{t}^{\max } \times u_{o n}^{g, t}\right) \forall t \in T P, g \in G N \\
& \text { if }\left(P_{o}^{s, g, t}-P_{o}^{s, g, t-1}\right)<0 \text { then }\left|P_{o}^{s, g, t}-P_{o}^{s, g, t-1}\right| \leq P_{r d}^{g} \\
& \forall s \in S C, t \in T P, g \in G N \\
& \text { if }\left(P_{o}^{s, g, t}-P_{o}^{s, g, t-1}\right)>0 \text { then }\left|P_{o}^{s, g, t}-P_{o}^{s, g, t-1}\right| \leq P_{r u}^{g} \\
& \forall s \in S C, t \in T P, g \in G N
\end{aligned}
$$

The binary variables showing shutdown and startup states of the generators are given by (16) and (17).

$$
\begin{aligned}
& \left\{\begin{array}{l}
\text { if }\left(u_{o n}^{g, t}-u_{o n}^{g, t-1}\right)<0 \text { then } u_{s d}^{g, t}=1 \\
\text { if }\left(u_{o n}^{g, t}-u_{o n}^{g, t-1}\right) \geq 0 \text { then } u_{s d}^{g, t}=0
\end{array} \forall t \in T P, g \in G N\right. \\
& \left\{\begin{array}{l}
\text { if }\left(u_{o n}^{g, t}-u_{o n}^{g, t-1}\right)>0 \text { then } u_{s u}^{g, t}=1 \\
\text { if }\left(u_{o n}^{g, t}-u_{o n}^{g, t-1}\right) \leq 0 \text { then } u_{s u}^{g, t}=0
\end{array} \forall t \in T P, g \in G N\right.
\end{aligned}
$$

The minimum up-time and down-time are demonstrated by (18) and (19).

$$
\begin{array}{ll}
\text { if } u_{s d}^{g, t}=1 \text { then } u_{s d}^{g,[t, t+1, \ldots, T s d]}=1 & \forall t \in T P, g \in G N \\
\text { if } u_{s u}^{g, t}=1 \text { then } u_{s u}^{g,[t, t+1, \ldots, T s u]}=1 & \forall t \in T P, g \in G N
\end{array}
$$

\section{B. Pumped-storage hydroelectricity}

The charging-discharging power (operation pattern) of the pumped-storage system is modeled by (20) [27].

$\left\{\begin{array}{ll}\text { if } & P_{\text {ces }}^{s, t}>0 \text { then } P_{\text {des }}^{s, t}=0 \\ \text { if } & P_{\text {des }}^{s, t}>0 \text { then } P_{\text {ces }}^{s, t}=0\end{array} \quad \forall s \in S C, t \in T P\right.$

The charging-discharging power must be less than the rated power of the storage system as described by (21) and (22). The efficiency of the storage system is defined by (23). The stored energy at each time interval is given by (24), and the rated capacity of the storage system is given by (25) [28].

$$
\begin{gathered}
P_{\text {ces }}^{s, t} \leq P_{\text {res }} \quad \forall s \in S C, t \in T P \\
P_{\text {des }}^{s, t} \leq P_{\text {res }} \quad \forall s \in S C, t \in T P \\
\eta_{e s}^{s}=\frac{\sum_{t \in T P} P_{\text {des }}^{s, t}}{\sum_{t \in T P} P_{\text {ces }}^{s, t}} \forall s \in S C
\end{gathered}
$$




$$
\begin{aligned}
& E_{e s}^{s, t}=E_{e s}^{s, t-1}+\left(P_{c e s}^{s, t}-P_{d e s}^{s, t}\right) \times T_{p} \quad \forall s \in S C, t \in T P \\
& E_{e s}^{s, t} \leq E_{r e s} \quad \forall s \in S C, t \in T P
\end{aligned}
$$

\section{Structure of the proposed model}

The flowchart of the proposed model is shown in Fig. 3. As shown in the flowchart, the model first takes the input data of the problem including the generating systems, energy storage system, demand response program, wind energy, and the network. The uncertain parameters are then modeled and the scenarios of performance are generated. The stochastic optimization problem is solved in GAMS software. If the constraints are satisfied, the optimal output is achieved and recorded; otherwise, the issued problems are fixed and the optimization problem is again solved. The outputs of the plan are shown after finding the global optimal solution for the optimization programming.
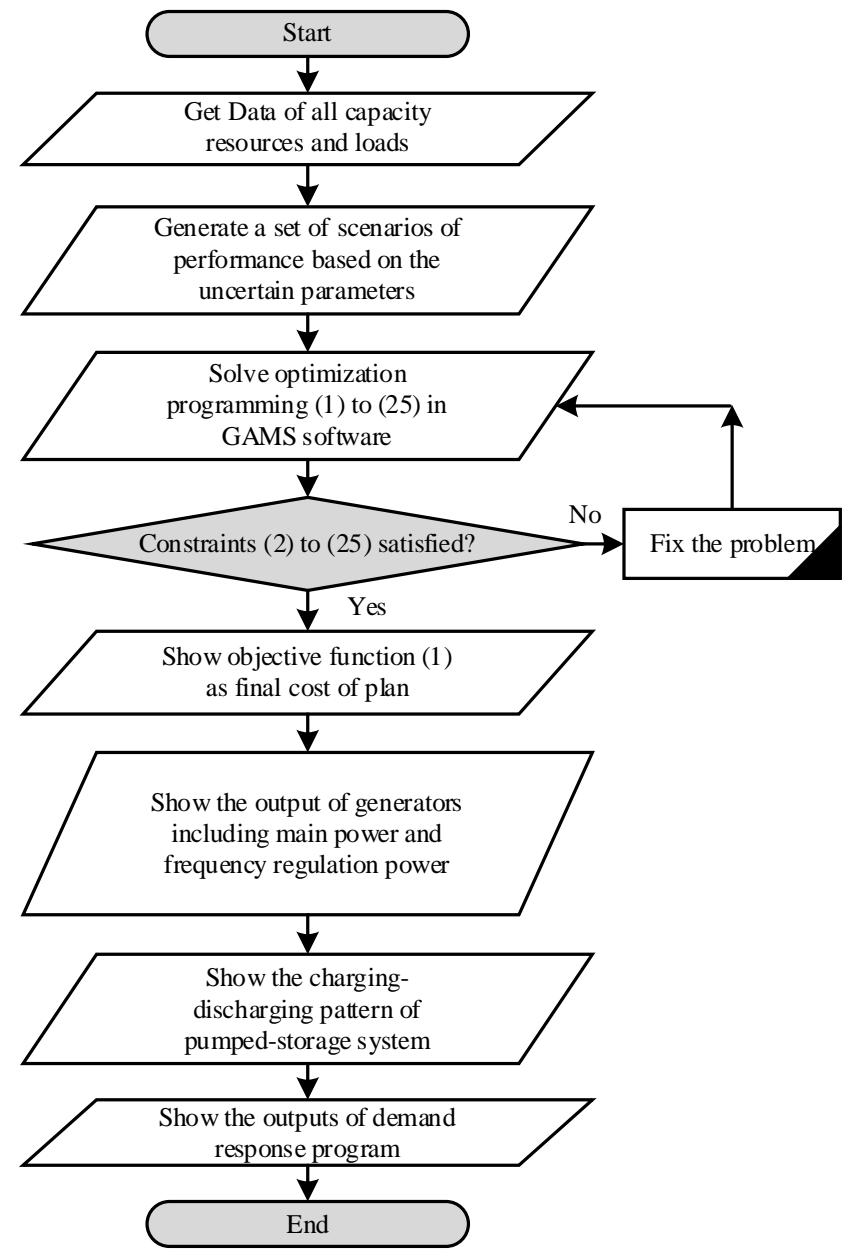

Fig. 3. Flowchart of the proposed model.

\section{TEST SYSTEM}

The test system includes 10 thermal generators and one large-scale wind farm. The fast response generators including generators 7 to 10 are allowed to take part in the frequency regulation capacity. The primary frequency control scheme is simulated and addressed in this paper.

The generating system including 10 thermal generators is listed in the Table 1 [26]. The generators data including fuel and startup costs are presented.
TABLE I

ECONOMIC DATA OF GENERATORS [26]

\begin{tabular}{cccc}
\hline $\begin{array}{c}\text { Generator } \\
\text { Number }\end{array}$ & $\begin{array}{c}\text { Fixed Cost } \\
(\$ / \mathrm{h})\end{array}$ & $\begin{array}{c}\text { Variable Cost } \\
(\$ / \mathrm{MWh})\end{array}$ & $\begin{array}{c}\text { Startup Cost } \\
(\$ / \mathrm{h})\end{array}$ \\
\hline 1 & 1000 & 16.19 & 9000 \\
2 & 970 & 17.26 & 10000 \\
3 & 950 & 17.5 & 11000 \\
4 & 700 & 16.6 & 1100 \\
5 & 680 & 16.5 & 1120 \\
6 & 450 & 19.7 & 1800 \\
7 & 370 & 22.26 & 340 \\
8 & 480 & 27.74 & 520 \\
9 & 660 & 25.92 & 60 \\
10 & 665 & 27.27 & 60 \\
\hline
\end{tabular}

The technical data of the generators are listed in the Table 2 [26]. These data include the maximum and minimum power of generators, ramp rates and minimum up-down times.

The system is integrated with one large scale $300 \mathrm{MW}$ wind farm. The profile for the output power of the wind farm is depicted in Fig. 1. It includes large ramping events.

TABLE II

TECHNICAL DATA OF GENERATORS [26]

\begin{tabular}{ccccc}
\hline $\begin{array}{c}\text { Generator } \\
\text { Number }\end{array}$ & $\begin{array}{c}\text { Pmin } \\
(\mathrm{MW})\end{array}$ & $\begin{array}{c}\text { Pmax } \\
(\mathrm{MW})\end{array}$ & $\begin{array}{c}\text { Ramp rate } \\
(\mathrm{MW} / \mathrm{h})\end{array}$ & $\begin{array}{c}\text { Minimum up and } \\
\text { down times (h) }\end{array}$ \\
\hline 1 & 150 & 455 & 200 & 8 \\
2 & 150 & 455 & 200 & 8 \\
3 & 150 & 455 & 160 & 8 \\
4 & 20 & 130 & 80 & 5 \\
5 & 20 & 130 & 80 & 5 \\
6 & 25 & 162 & 80 & 6 \\
7 & 20 & 80 & 80 & 2 \\
8 & 25 & 85 & 80 & 2 \\
9 & 55 & 55 & 55 & 1 \\
10 & 55 & 55 & 55 & 1 \\
\hline
\end{tabular}

The daily loading profile is listed in the Table 3 [26]. The load power is presented in one-hour time-interval. The time domain simulation of the model is performed based on the two time-intervals including time interval for energy dispatch (one hour) and time interval for wind power operation (15-minute).

TABLE III

LOADING PROFILE OF THE NETWORK [26]

\begin{tabular}{cccccc}
\hline Hour & $\begin{array}{c}\text { Power } \\
\text { (MW) }\end{array}$ & Hour & Power (MW) & Hour & Power (MW) \\
\hline 1 & 700 & 9 & 1300 & 17 & 1000 \\
2 & 750 & 10 & 1400 & 18 & 1100 \\
3 & 850 & 11 & 1410 & 19 & 1200 \\
4 & 950 & 12 & 1500 & 20 & 1400 \\
5 & 1000 & 13 & 1400 & 21 & 1300 \\
6 & 1100 & 14 & 1300 & 22 & 1100 \\
7 & 1150 & 15 & 1300 & 23 & 900 \\
8 & 1200 & 16 & 1050 & 24 & 800 \\
\hline
\end{tabular}

The other data of the planning such as load curtailment cost and level, pumped-storage power and capacity, and reserve capacities are listed in Table $4[29,30]$.

TABLE IV

INPUT DATA OF THE PLANNING $[29,30]$

\begin{tabular}{lc}
\multicolumn{2}{c}{ INPUT DATA OF THE PLANNING [29, 30] } \\
\hline \multicolumn{1}{c}{ Parameter } & Level \\
\hline Load curtailment cost (\$/MWh) & 100 \\
Duration of time periods (Minute) & 15 \\
Permitted load curtailment level (\%) & 2 \\
Rated power of pumped-storage (MW) & 15 \\
Rated capacity of pumped-storage (MWh) & 50 \\
Efficiency of pumped-storage (\%) & 60 \\
Spinning reserve capacity (percentage of loading) & 20 \\
Frequency regulation capacity (percentage of loading) & 15 \\
\hline
\end{tabular}

\section{SIMULATION RESULTS}

The unit commitment model is simulated together with different technologies and components such as demand response program, pumped-storage hydroelectricity, wind ramping, and wind uncertainty. 


\section{A. Outputs of unit commitment}

In this section, the frequency regulation capacity is set on $15 \%$ of loading power. The demand response and energy storage are not included. Table 5 shows the output power produced by generators. The 24-hour energy dispatch is carried out and generators 1 to 6 supply the load demand. At some hours, the output power is zero, and the generators are OFF. At some hours, some generators only supply the reserve capacities and their capacity is not used to supply the demand. Such generators do not produce power and they work on no-load condition. Their capacity is available to the system operator within a short-time-interval to supply the load demand. In this case, the output power of the generators is equal to the no-load power that is $0.002 \mathrm{MW}$ in the proposed test system.

The capacity of generators 7 to 10 during all 24-hour is devoted to the reserve capacities and generators 4 and 6 work on the no-loading condition at some hours. The noload operation is because of minimum up-time and downtime of the generators and they cannot uncommitted during short time periods. As a result, the planning allows them operate on no-loading and keeps them ready for the next periods. In this case, the daily cost is 597543.959 (\$/day).

\section{TABLE V}

OUTPUT POWER PRODUCED BY GENERATORS

\begin{tabular}{|c|c|c|c|c|c|c|c|}
\hline Hour & G1 & G2 & G3 & G4 & G5 & G6 & $\begin{array}{c}\text { G7 } \\
\text { to G10 }\end{array}$ \\
\hline 1 & 411.8 & 267.4 & 0 & 0 & 0 & 0 & 0.002 \\
\hline 2 & 404.2 & 317.4 & 0 & 0 & 0 & 0 & 0.002 \\
\hline 3 & 410 & 367.4 & 0 & 0 & 0 & 0 & 0.002 \\
\hline 4 & 455 & 417.4 & 40 & 0 & 0 & 0 & 0.002 \\
\hline 5 & 442 & 403.4 & 80 & 0 & 0 & 0 & 0.002 \\
\hline 6 & 392 & 353.4 & 112.9 & 0 & 0 & 0 & 0.002 \\
\hline 7 & 442 & 403.4 & 152.9 & 0 & 20 & 0 & 0.002 \\
\hline 8 & 455 & 453.4 & 192.9 & 0 & 40 & 0 & 0.002 \\
\hline 9 & 455 & 455 & 232.9 & 0 & 60 & 0 & 0.002 \\
\hline 10 & 455 & 455 & 272.9 & 0 & 80 & 0 & 0.002 \\
\hline 11 & 405 & 405 & 232.9 & 0 & 66.9 & 0 & 0.002 \\
\hline 12 & 455 & 455 & 202.9 & 0 & 86.9 & 0 & 0.002 \\
\hline 13 & 455 & 405 & 162.9 & 0 & 100.9 & 0 & 0.002 \\
\hline 14 & 411.9 & 355 & 122.9 & 0 & 110 & 0 & 0.002 \\
\hline 15 & 455 & 405 & 150.9 & 20 & 130 & 20 & 0.002 \\
\hline 16 & 405 & 355 & 110.9 & 0.002 & 110 & 0.002 & 0.002 \\
\hline 17 & 427.7 & 305 & 70.98 & 20 & 90 & 0.002 & 0.002 \\
\hline 18 & 400.4 & 355 & 110.9 & 40 & 90 & 0.002 & 0.002 \\
\hline 19 & 438.4 & 405 & 150.9 & 60 & 110 & 18.34 & 0.002 \\
\hline 20 & 455 & 455 & 190.9 & 80 & 130 & 38.34 & 0.002 \\
\hline 21 & 455 & 405 & 150.9 & 84.5 & 130 & 40.00 & 0.002 \\
\hline 22 & 405 & 355 & 110.9 & 64.5 & 110 & 20.00 & 0.002 \\
\hline 23 & 355 & 305 & 70.9 & 44.5 & 90 & 0.002 & 0.002 \\
\hline 24 & 383.2 & 255 & 49.9 & 24.5 & 70 & 0.002 & 0.002 \\
\hline
\end{tabular}

The frequency regulation capacity and spinning reserve are depicted in the Fig. 4 together with load demand profile. The frequency regulation capacity is reserved at all hours of the day as shown by the results. The frequency regulation capacity is set to $15 \%$ of loading power. The spinning reserve is $15 \%$ of the loading power and it is also reserved over the day hour. Such reserve capacities keep the system ready for ramping events and incidents.

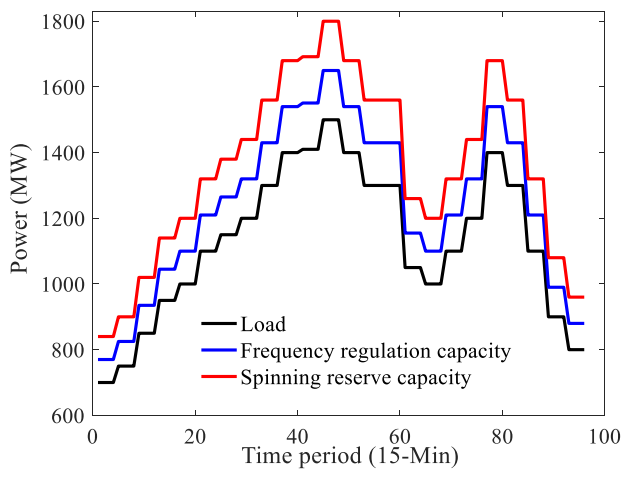

Fig. 4. Load demand, frequency regulation and spinning reserve.

\section{B. Frequency regulation service}

The produced powers by generators 7 and 9 are shown in Fig. 5. These generators are responsible for frequency regulation under generation-demand imbalances and their capacities are reserved for the frequency regulation. It is clear that their power production change depending on the wind power fluctuations and they change their produced powers to deal with wind power uncertainties.

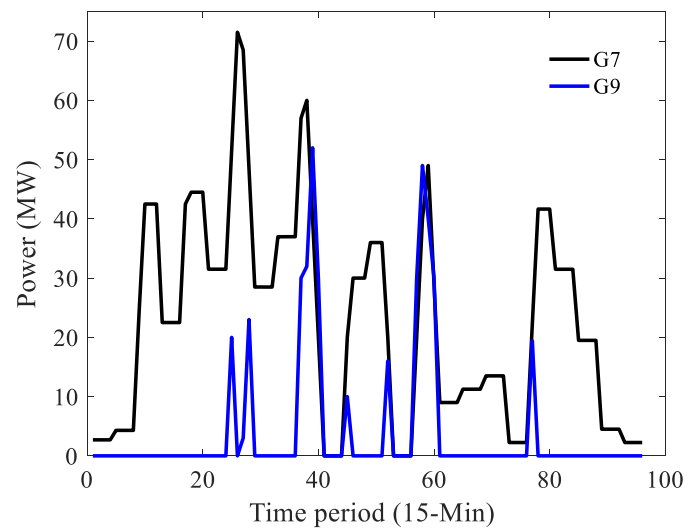

Fig. 5. Power by generators 7 and 9 to regulate frequency.

The power of generator 7 under different wind power scenarios is shown in the Fig. 6. This generator mitigates the wind power fluctuations by changing its production pattern. Together with decreasing wind power, the output power of generator 7 is increased and vice-versa.

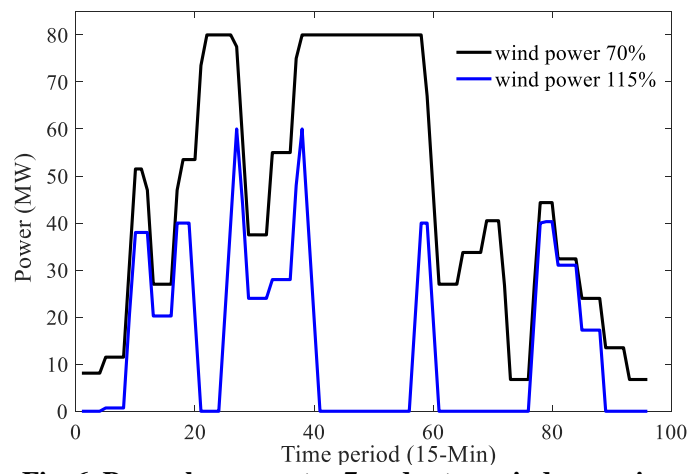

Fig. 6. Power by generator 7 under two wind scenarios.

\section{Wind integration level}

The wind integration means the wind power penetration is the fraction of energy generated by wind energy compared to the total generating energy in the system. Table 6 lists the operational costs under different wind integration levels. The initial wind integration level on the grid is $300 \mathrm{MW}$. The other wind integration levels are compared against the initial wind integration level (i.e., $300 \mathrm{MW}$ ). The results demonstrate that the optimal level for the wind integration is $300 \mathrm{MW}$, where it comprises minimum operational cost.

With a higher wind integration level (e.g., $320 \mathrm{MW}$ ) a larger wind ramping power is injected into the system. The system, therefore needs a higher ramping capacity. The thermal generators must operate on the maximum ramp rate to handle wind ramping power. Such operation in non-optimal and increases the operational cost compared to the initial wind integration level (i.e., $300 \mathrm{MW}$ ). The maximum wind integration is $320 \mathrm{MW}$ because the frequency regulation reserve has a limited capacity to deal with wind fluctuations. When wind fluctuations are larger than the frequency regulation capacity, the frequency drops below the permitted range and the operation is infeasible. 
TABLE VI

OPERATIONAL COST UNDER DIVERSE WIND INTEGRATION LEVELS Wind integration level (MW) Operational cost (\$/day)

$\begin{array}{lc}280 & 598225.560 \\ 300 & 597543.959 \\ 320 & 599017.588 \\ 340 & \text { Infeasible }\end{array}$

The wind integration and operational cost are a function of frequency regulation capacity and ramp rate of generators. The systems with a higher frequency regulation capacity can be integrated with larger wind power. This point is shown in Table 7. Two cases are studied; case 1 is the nominal case with a $15 \%$ frequency regulation capacity and the second case with a frequency regulation capacity equal to $5 \%$. In the second case, both the wind integration level and operational cost are reduced compared to the first case. The second case needs a lower capacity for the frequency regulation and the capacity of generators is used to supply the demand resulting in a lower operational cost. However, the system of case 2 cannot handle large-scale imbalances between generation and load and its operation will be infeasible under largescale wind fluctuations.

TABLE VII

\begin{tabular}{cccc}
\multicolumn{4}{c}{ DIFFERENT CAPACITIES FOR FREQUENCY REGULATION } \\
\hline & $\begin{array}{c}\text { Frequency } \\
\text { regulation capacity }\end{array}$ & $\begin{array}{c}\text { Operational cost } \\
(\$ / \text { day) }\end{array}$ & $\begin{array}{c}\text { Maximum wind } \\
\text { integration level }\end{array}$ \\
\hline Case 1 & 15\% of loading & 597543.959 & 330 \\
Case 2 & $5 \%$ of loading & 592363.322 & 170 \\
\hline
\end{tabular}

\section{Demand response program}

In this section, the demand response program is added to the unit commitment. This program is modeled by load curtailment. Table 8 summarizes the load curtailment versus wind penetration levels. The results demonstrate that the demand response program can increase wind penetration level to more than $350 \mathrm{MW}$. The operation under larger wind powers like 370 is infeasible.

\section{TABLE VIII}

PERCENTAGE OF LOAD CURTAILMENT UNDER DIFFERENT WIND PENETRATION LEVELS

\begin{tabular}{cc} 
PENETRATION LEVELS \\
\hline $\begin{array}{c}\text { Wind penetration level } \\
(\mathrm{MW})\end{array}$ & $\begin{array}{c}\text { Demand response program } \\
\text { (Percentage of load curtailment) }\end{array}$ \\
\hline \multirow{3}{*}{300} & Time interval 20 $=0.7$ \\
& Time interval 25 $=1.1$ \\
& Time interval $40=0.6$ \\
Time interval $57=0.4$ \\
Time interval $60=1.9$ \\
\hline 350 & Time interval 20 $=1.0$ \\
& Time interval 25 $=1.8$ \\
& Time interval $40=1.4$ \\
& Time interval 57 $=0.8$ \\
& Time interval $60=0.3$ \\
\hline 370 & Infeasible \\
\hline
\end{tabular}

\section{E. Pumped-storage system}

In this stage, the pumped-storage is added to the unit commitment. Table 9 shows the outputs of the plan with pumped-storage under different wind penetration levels. It is shown that the storage technology increases the wind level to $410 \mathrm{MW}$. The energy storage system properly deals with wind ramping and wind uncertainty and enables the system to have more wind penetration level.

TABLE IX

\begin{tabular}{cccc} 
SYSTEM WITH PUMPE-STORAGE UNDER WIND PENETRATION LEVELS \\
\hline $\begin{array}{c}\text { Wind penetration } \\
\text { level (MW) }\end{array}$ & $\begin{array}{c}\text { Operational } \\
\text { cost }(\$ / \text { day })\end{array}$ & $\begin{array}{c}\text { Demand response } \\
\text { program }\end{array}$ & $\begin{array}{c}\text { Pumped-storage } \\
\text { system }\end{array}$ \\
\hline 300 & 578443.644 & Yes & Yes \\
350 & 574502.928 & Yes & Yes \\
400 & 587878.088 & Yes & Yes \\
410 & 589827.171 & Yes & Yes \\
420 & Infeasible & - & - \\
\hline
\end{tabular}

The daily operation of pumped-storage system is shown in Fig. 7. The storage device stores the surplus of wind energy during ramp-up and discharges such energy during rampdown. It is clear that such efficient charging-discharging patten properly deal with wind ramping events and uncertainties.

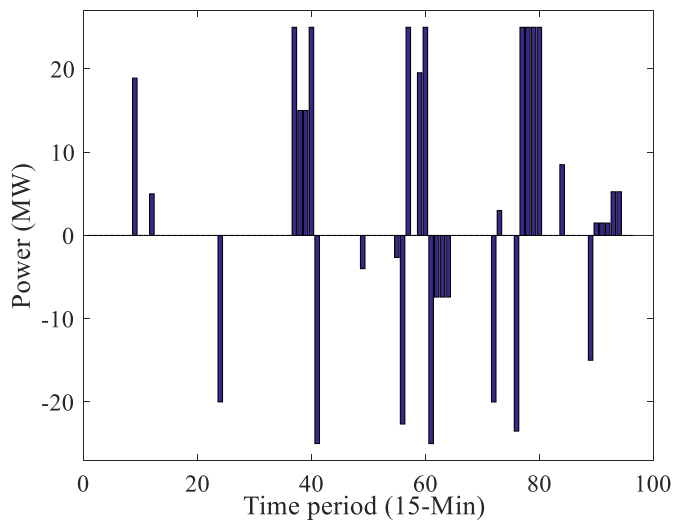

Fig. 7. Charging-discharging regime of pumped-storage.

\section{F. Comparative study on different models}

The different models of problem including unit commitment without demand response and pumped-storage, unit commitment with demand response without pumped-storage, unit commitment without demand response with pumpedstorage, and unit commitment with both demand response and pumped-storage are listed and compared in the Table 10. The results verify that the unit commitment with both demand response and pumped-storage has the best operation with minimum operating cost and maximum wind penetration level.

TABLE X

COMPARISON OF DIFFERENT CASES

\begin{tabular}{ccc}
\hline Case & $\begin{array}{c}\text { Operational cost with wind } \\
\text { power 300 MW (\$/day) }\end{array}$ & $\begin{array}{c}\text { Maximum wind } \\
\text { penetration level }\end{array}$ \\
\hline $\begin{array}{c}\text { Without demand response and } \\
\text { pumped-storage }\end{array}$ & 597543.959 & 330 \\
\hline Only demand response & 585884.191 & 360 \\
\hline Only Pumped-storage system & 578907.459 & 380 \\
\hline $\begin{array}{c}\text { With both demand response and } \\
\text { pumped-storage }\end{array}$ & 578443.644 & 410 \\
\hline
\end{tabular}

\section{G. Comparing wind power ramping}

In order to compare the impacts of ramping event on wind penetration level, two cases including wind power with and without large ramping are simulated and compared in the Fig. 8. It is shown that the model without large ramping can penetrate large wind power because it needs less frequency regulation capacity to handle the ramping events. But considering large ramps in the wind power reduces the wind penetration level by about $25 \%$.

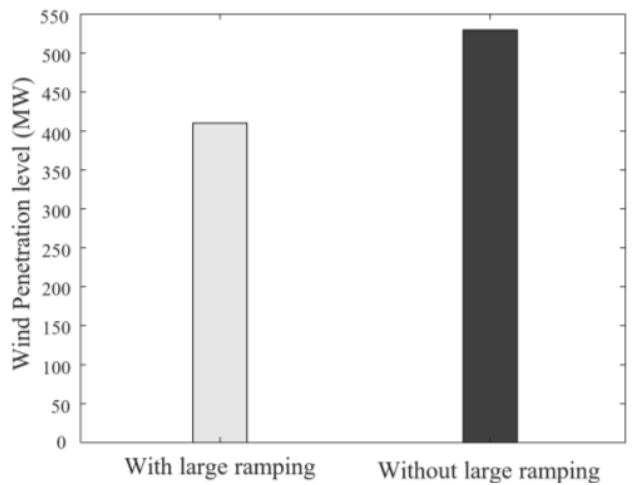

Fig. 8. Impacts of wind power ramping on wind penetration level. 


\section{CONCLUSIONS}

This paper addresses unit commitment under large ramping and intermittency of wind power. Three options are proposed to deal with wind issues including frequency regulation capacity, demand response, and energy storage system. The generators that work as reserve capacities change their output power to cope with wind uncertainties and ramping. Increasing wind power also increases the operational cost. Decreasing the frequency regulation capacity reduces both the wind penetration level and operational cost. But a system with low-frequency regulation capacity cannot handle large-scale wind fluctuations. A demand response program can increase the wind penetration level by about $10 \%$. The pumped-storage can increase the wind penetration level by about $16 \%$. Both the demand response and pumped-storage reduce the operational cost by $5 \%$ and increase wind integration by about $25 \%$. The results confirm that wind integration level is increased up to $200 \%$ when large wind ramping is not included.

\section{REFERENCES}

[1] A. A. Almehizia, H. M. K. Al-Masri, and M. Ehsani, "Integration of Renewable Energy Sources by Load Shifting and Utilizing Value Storage," IEEE Transactions on Smart Grid, vol. 10, no. 5, pp. 4974 4984, 2019.

[2] M. Cui, V. Krishnan, B. Hodge, and J. Zhang, "A Copula-Based Conditional Probabilistic Forecast Model for Wind Power Ramps," IEEE Transactions on Smart Grid, vol. 10, no. 4, pp. 3870-3882, 2019.

[3] M. Cui, J. Zhang, C. Feng, A. R. Florita, Y. Sun, and B.-M. Hodge, "Characterizing and analyzing ramping events in wind power, solar power, load, and netload," Renewable Energy, vol. 111, pp. 227-244, 2017.

[4] E. Yao, V. W. Wong, and R. Schober, "Robust frequency regulation capacity scheduling algorithm for electric vehicles," IEEE Transactions on Smart Grid, vol. 8, no. 2, pp. 984-997, 2017.

[5] H. Wu, M. Shahidehpour, A. Alabdulwahab, and A. Abusorrah, "Thermal Generation Flexibility With Ramping Costs and Hourly Demand Response in Stochastic Security-Constrained Scheduling of Variable Energy Sources," IEEE Transactions on Power Systems, vol. 30, no. 6, pp. 2955-2964, 2015.

[6] M. Cui, J. Zhang, A. R. Florita, B. Hodge, D. Ke, and Y. Sun, "An Optimized Swinging Door Algorithm for Identifying Wind Ramping Events," IEEE Transactions on Sustainable Energy, vol. 7, no. 1, pp. $150-162,2016$

[7] E. D. Castronuovo and J. A. P. Lopes, "On the optimization of the daily operation of a wind-hydro power plant," IEEE Transactions on Power Systems, vol. 19, no. 3, pp. 1599-1606, 2004.

[8] Y. J. A. Zhang, C. Zhao, W. Tang, and S. H. Low, "Profitmaximizing planning and control of battery energy storage systems for primary frequency control," IEEE Transactions on Smart Grid, vol. 9, no. 2, pp. 712-723, 2018.

[9] S. Acharya, M. S. E. Moursi, and A. Al-Hinai, "Coordinated Frequency Control Strategy for an Islanded Microgrid With Demand Side Management Capability," IEEE Transactions on Energy Conversion, vol. 33, no. 2, pp. 639-651, 2018.

[10] V. K. Tumuluru and D. H. Tsang, "A two-stage approach for network constrained unit commitment problem with demand response," IEEE Transactions on Smart Grid, vol. 9, no. 2, pp. 1175$1183,2018$.

[11] B. C. Ummels, M. Gibescu, E. Pelgrum, W. L. Kling, and A. J. Brand, "Impacts of Wind Power on Thermal Generation Unit Commitment and Dispatch," IEEE Transactions on Energy Conversion, vol. 22, no. 1, pp. 44-51, 2007.

[12] J. F. Restrepo and F. D. Galiana, "Unit commitment with primary frequency regulation constraints," IEEE Transactions on Power Systems, vol. 20, no. 4, pp. 1836-1842, 2005.

[13] H. Ahmadi and H. Ghasemi, "Security-Constrained Unit Commitment With Linearized System Frequency Limit Constraints," IEEE Transactions on Power Systems, vol. 29, no. 4, pp. 1536-1545, 2014.

[14] M. Jadidbonab, B. Mohammadi-Ivatloo, M. Marzband, and P. Siano, "Short-term Self-Scheduling of Virtual Energy Hub Plant within Thermal Energy Market," IEEE Transactions on Industrial Electronics, pp. 1-1, 2020.
[15] H. R. Gholinejad, A. Loni, J. Adabi, and M. Marzband, "A hierarchical energy management system for multiple home energy hubs in neighborhood grids," Journal of Building Engineering, vol. 28, p. $101028,2020 / 03 / 01 / 2020$

[16] M. Nazari-Heris, M. A. Mirzaei, B. Mohammadi-Ivatloo, M. Marzband, and S. Asadi, "Economic-environmental effect of power to gas technology in coupled electricity and gas systems with priceresponsive shiftable loads," Journal of Cleaner Production, vol. 244, p. $118769,2020 / 01 / 20 / 2020$.

[17] M. Marzband, F. Azarinejadian, M. Savaghebi, E. Pouresmaeil, J. M. Guerrero, and G. Lightbody, "Smart transactive energy framework in grid-connected multiple home microgrids under independent and coalition operations," Renewable Energy, vol. 126, pp. 95-106, 2018/10/01/ 2018.

[18] R. Das et al., "Multi-objective techno-economic-environmental optimisation of electric vehicle for energy services," Applied Energy, vol. 257, p. 113965, 2020/01/01/ 2020.

[19] M. A. Mirzaei, A. Sadeghi-Yazdankhah, B. Mohammadi-Ivatloo, M. Marzband, M. Shafie-khah, and J. P. S. Catalão, "Integration of emerging resources in IGDT-based robust scheduling of combined power and natural gas systems considering flexible ramping products," Energy, vol. 189, p. 116195, 2019/12/15/ 2019.

[20] R. Sevlian and R. Rajagopal, "Detection and statistics of wind power ramps," IEEE Transactions on Power Systems, vol. 28, no. 4, pp. 3610-3620, 2013

[21] T. Ouyang, X. Zha, and L. Qin, "A survey of wind power ramp forecasting," Energy and Power Engineering, vol. 5, no. 04, p. 368, 2013.

[22] G. Ren, J. Liu, J. Wan, Y. Guo, and D. Yu, "Overview of wind power intermittency: Impacts, measurements, and mitigation solutions," Applied Energy, vol. 204, pp. 47-65, 2017.

[23] F. D. Mohammadi, H. K. Vanashi, and A. Feliachi, "State-Space Modeling, Analysis, and Distributed Secondary Frequency Control of Isolated Microgrids," IEEE Transactions on Energy Conversion, vol. 33, no. 1, pp. 155-165, 2018.

[24] Y. G. Rebours, D. S. Kirschen, M. Trotignon, and S. Rossignol, "A survey of frequency and voltage control ancillary services-Part I: Technical features," IEEE Transactions on power systems, vol. 22, no. 1, pp. 350-357, 2007.

[25] R. Hemmati, H. Saboori, and S. Saboori, "Assessing wind uncertainty impact on short term operation scheduling of coordinated energy storage systems and thermal units," Renewable Energy, vol. 95, pp. 74-84, 9// 2016.

[26] M. Carrión and J. M. Arroyo, "A computationally efficient mixedinteger linear formulation for the thermal unit commitment problem," IEEE Transactions on power systems, vol. 21, no. 3, pp. 1371-1378, 2006

[27] H. Mehrjerdi and R. Hemmati, "Electric vehicle charging station with multilevel charging infrastructure and hybrid solar-batterydiesel generation incorporating comfort of drivers," Journal of Energy Storage, vol. 26, pp. 1009-24, 2019/12/01/ 2019.

[28] R. Hemmati and H. Mehrjerdi, "Stochastic Linear Programming for Optimal Planning of Battery Storage Systems Under UnbalancedUncertain Conditions," Journal of Modern Power Systems and Clean Energy, vol. 8, no. 3, pp. 1-10, 2020.

[29] H. Mehrjerdi and R. Hemmati, "Energy and uncertainty management through domestic demand response in the residential building," Energy, p. 116647, 2019/11/27/ 2019

[30] H. Mehrjerdi and R. Hemmati, "Stochastic model for electric vehicle charging station integrated with wind energy," Sustainable Energy Technologies and Assessments, vol. 37, p. 100577, 2020/02/01/ 2020. 